\title{
How did Nepal Reduce the Maternal Mortality? A Result from Analysing the Determinants of Maternal Mortality
}

\author{
Karkee R. \\ School of Public Health and Community Medicine, BP Koirala Institute of Health Sciences, Dharan, Nepal.
}

\begin{abstract}
Nepal reportedly reduced the maternal mortality ratio by $48 \%$ within one decade between 1996-2005 and received the Millennium development goal award for this. However, there is debate regarding the accuracy of this figure. On the basis of framework of determinants of maternal mortality proposed by McCarthy and Maine in 1992 and successive data from Nepal demographic health survey of 1996, 2001 and 2006, a literature analysis was done to identify the important factors behind this decline. Although facility delivery and skilled birth attendants are acclaimed as best strategy of reducing maternal mortality, a proportionate increase in these factors was not found to account the maternal mortality rate reduction in Nepal. Alternatively, intermediate factors particularly women awareness, family planning and safe abortion might have played a significant role. Hence, Nepal as well as similar other developing countries should pay equal attention to such intermediate factors while concentrating on biomedical care strategy.
\end{abstract}

Keywords: Determinants, maternal mortality, Nepal, reduction

\section{BACKGROUND}

In September 2010, Nepal received the Millennium Development Goal (MDG) award from the United Nations for its exceptional achievement in reducing maternal mortality. ${ }^{1}$ Nepal had one of the highest maternal mortality ratio (MMR) in the past decades. World Health Organisation (WHO) and United Nation Development Programme (UNDP) estimated it as 1500 in 1990, 826 in 1995 and 670 in 2005 while National Demographic Health survey (NDHS) calculated it as 515 in 1991, 539 in 1996 and 281 in 2006. Further, a recent maternal mortality and morbidity study estimated the figure as 229 in 2010, using a surveillance system where community informants reported births and deaths of women of reproductive age. ${ }^{2}$ Since Nepal does not have a functioning complete death registration system of maternal deaths, maternal mortality estimation is difficult. NDHS 2006 of Nepal used direct sisterhood method that asks respondents to provide information about their sisters; while WHO in 2005 estimated MMR by means of regression analysis. Estimation of maternal mortality is methodologically varied and may be affected by possible under-reporting or chances of underestimation in poor surveillance system. ${ }^{3}$

On the other hand, there is debate regarding the extent of decline in the maternal mortality during the civil war period of 1996-2005. 2,4,5 During the war period, provision of adequate health services in rural areas was affected due to destruction of health posts and threatening to health workers. This had a negative impact on population health. ${ }^{6}$ Nepal has still large gender disparity, with women often experiencing sexual violence in their own houses and thus, losing their control over their own reproductive life. ${ }^{7}$ Further,

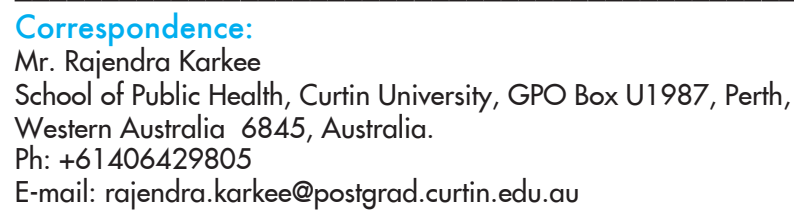


Karkee. How did Nepal Reduce the Maternal Mortality?

Nepal's hilly geographical terrain has made it difficult to provide health services to rural villages. Since the mortality reduction is an impact indicator of maternal health improvement, the reduction must come through input as well as process indicators i.e the various determinants of maternal mortality. The aim of this paper is to analyse the determinants of maternal mortality in the context of maternal mortality reduction in Nepal so as to explore the important factors behind the significant decline of MMR in Nepal over the past decade.

\section{METHODS}

Electronic databases of Medline, PubMed, Science Direct, CINAHAL, and Biomed Central were searched with key words: Nepal, maternal health improvement, maternal mortality, maternal health service, safe motherhood, progress, MDGs. Grey literature was searched with Google search engine to retrieve relevant governmental and non-governmental websites, study reports, documents, and policies. All types of articles including original, review, editorial, commentary, and national newspaper reports were considered. Data was derived mainly from successive Demographic Health Survey of Nepal 1996, 2001 and 2006 for comparison on related determinants of maternal mortality. Framework of determinants of maternal mortality proposed by McCarthy and Maine in 1992 was used. ${ }^{8}$

Explanation about determinants of maternal mortality was given based on the framework of McCarthy and Maine and then, analysis of progress on those determinants in Nepal was done based on data (Table 1) followed by a conclusion with plausible factors associated with the decline.

\section{RESULTS AND DISCUSSION}

\section{Determinants of maternal mortality}

McCarthy and Maine provided a detailed framework of determinants to analyse maternal mortality and morbidity. ${ }^{8}$ They identified three types of determinants: distal, intermediate, and proximal or immediate outcomes. Distal determinants include women's status in family and community such as education, occupation, income, and social and legal autonomy; family's status in community such as family income, land, education and occupation of family members; and community's status such as community tradition and resources. Intermediate determinants include health and reproductive status of women, and accessibility and utilisation of health services. These two types of determinants operate to produce immediate cause of maternal mortality, which starts from pregnancy and might end in pregnancy related complications such as haemorrhage, infection, pregnancy-induced hypertension, obstructed labour. According to this framework, all strategies to improve maternal health should target either: i) to reduce the likelihood that a woman will become pregnant; or ii) to reduce the likelihood that a woman will experience a serious complication of pregnancy or childbirth; or iii) to improve the outcomes for women with complications. Therefore, it follows that family planning or late marriage and early detection, management and preparedness of birth can contribute to reduction of MMR and improvement of maternal health.

On the other side, most maternal deaths in developing countries were reported during labour, delivery or the first 24 hours of postpartum, with obstetric haemorrhage being the main immediate cause. ${ }^{10} \mathrm{~A}$ recent 2009 study of maternal mortality and morbidity in eight districts of Nepal reports that haemorrhage is the leading cause and that percentage contribution of eclampsia, abortion related complication, gastroenteritis and anaemia have more than the similar study in Nepal in $1998 .^{2}$ So, if the immediate causes are managed, maternal mortality can be reduced significantly. Accordingly, the universal maternal mortality reduction strategy is mainly focussed on intrapartum and complication related care. This care is best provided at health facility, especially at primary level, whereby women can have access of skilled care easily by skilled birth attendants. ${ }^{11,}{ }^{12}$ While such biomedical strategy is helpful to save the mother's life, the real sustainable success criteria should also include the indicators that show the reduction in the likelihood that a woman will become pregnant or that she will experience a complication. In developing countries like Nepal, early marriage, unmet need of family planning and unsafe abortion is still high. ${ }^{13},{ }^{14}$ This means, we must look further in distal and intermediate determinants as well to make a sustainable achievement rather than narrow focus on immediate outcome curative strategy.

\section{Socio-cultural environment in Nepal and distal factors}

Nepal can be described as a diversified country in terms of geography, ethnicity, languages and culture. Many deeply rooted cultural practices are still prevalent, which might have negative implication for expectant mother and new child. For examples, postpartum women are forbidden from leaving the house or touching anyone for at least 11 days after delivery; and there is superstitious belief that women should not cross a river during pregnancy. Care seeking in pregnancy and childbirth is often perceived shameful. ${ }^{2}$ More than $80 \%$ of land in Nepal is rural area covered with hills and mountains, which are very difficult to access and provide challenges for health service provision. ${ }^{15}$ The difficult terrain is particularly challenging while accessing maternity services. Though many rural areas 
Karkee. How did Nepal Reduce the Maternal Mortality?

have recently been connected with road network, these roads are often not functional throughout the year and reliable and efficient vehicles may not be available when required. The transport of women just before and after the delivery to the nearest equipped birthing centre is expensive and troublesome because the pregnant women should be accompanied by her relatives, which increases the logistics in various ways such as lodging if the facility is not near.

Overall, Nepalese society is patriarchal and male dominated, where women have limited autonomy for household decision including their own reproductive health decision and resources handling. ${ }^{16}$ Some women of lower caste are denied access to skilled birth attendance. Bruson, from her ethnographic study in a semi-urban area of Kathmandu concludes that women still cannot decide and demand the need of obstetric care and men are not involved in the delivery issue until there is urgency. ${ }^{17}$ There is no significant increase in women's literacy from 1996 to 2006. Similarly, age at marriage and age at first birth of women has also not changed much (Table 1). Early marriage and early motherhood are still quite common among Nepalese women, especially in rural and marginalised areas. ${ }^{18}$ Poor nutrition contributes to poor maternal health with various obstetric complications. Women's and children's nutritional condition have progressed very little over the decade (Table 1). The 2006 Demographic survey reports that still $42 \%$ of pregnant women are anaemic in Nepal. Christen et al. reports that low maternal age, malnutrition (thin arm) and illness in early to mid-gestation were associated with risk of death during pregnancy and the first year postpartum in rural Nepal. ${ }^{19}$

However, women's situation has also progressed in past few years. Radio programmes on maternal health, maternal health information and mother's education programme has contributed to raise women's status. ${ }^{20}$ Women's empowerment has increased in Nepal and can be attributed to the adaptation of inclusive gender policy, which allow women in civic participation and in household property. Women having land are significantly more likely to influence the household decisions with improved nutrition for their children. ${ }^{21}$ However, much benefit may not be guaranteed until such policies are truly translated into action under prevailing social and cultural environments.

Total fertility rate has reduced while contraceptive prevalence rate has increased from 1996 to 2006. One of the plausible explanations is that the spouses of many married couples in Nepal are abroad for years for employment, which might have played role in fertility reduction and thus less pregnancy. However, unmet need for family planning has reduced slightly. Many
Table 1. Progress on various determinants of MMR in Nepal between 1996-2006 ${ }^{9}$

\begin{tabular}{lccc}
\hline Determinants & 1996 & 2001 & 2006 \\
\hline $\begin{array}{l}\text { Women's status } \\
\text { Illiterate ever-married }\end{array}$ & 80 & 72 & 63 \\
$\begin{array}{l}\text { women (\%) } \\
\text { Female school } \\
\text { attendance } 6 \text { years and } \\
\text { above (\%) }\end{array}$ & 32 & 40 & 51 \\
$\begin{array}{l}\text { Nutritional status } \\
\text { BMI } 18.5 \text { in ever- } \\
\text { married women (\%) }\end{array}$ & 28 & 27 & 24 \\
$\begin{array}{l}\text { Stunted children }<5 \\
\text { years (\%) }\end{array}$ & 56 & 57 & 49
\end{tabular}

Reproductive status

Age at marriage (in

years)

Age at first birth (in

years)

$\begin{array}{ccc}16.4 & 16.6 & 17.2 \\ 19.8 & 19.9 & 19.9 \\ 4.6 & 4.1 & 3.1 \\ 26 & 35.4 & 44.2 \\ 31.4 & 27.8 & 24.6\end{array}$

CPR (\%)

$89 \mathrm{PHCC} \quad 168 \mathrm{PHCC}$

Acces to services

Birthing centres (No.)

(2004-5) (2007-8)

$\begin{array}{lll}\text { BEOC sites (No.) } & - & 13(2004-5)^{68(2007-8)} \\ \text { CEOC sites (No.) } & 34 \text { (2004-5) 51(2007-8) }\end{array}$

Use of services

Antenatal care $(4$

visits)

Delivery in health

facility

$9 \%$

$8 \%$

$9 \%$

Postnatal care

BMI (Body Mass Index), TFR (Total Fertility Rate), CPR (Contraceptive Prevalence Rate), FP (Family Planning), BEOC (Basic Emergency Obstetric Care), CEOC (Comprehensive Emergency Obstetric Care), PHCC (Primary Health Care Centre)

pregnancies in Nepal are unplanned and unwanted. ${ }^{22}$ A hospital-based study conducted in 1984-85 at five major hospitals in and around Kathmandu valley reported 1576 cases of abortion related complications. ${ }^{23}$ According to NDHS survey 2006, about one-third of pregnancies is unplanned and thus might seek abortion. Chances of abortion are high when the foetus is 
Karkee. How did Nepal Reduce the Maternal Mortality?

female. ${ }^{24}$ Informal and unmanaged abortion is one of leading causes of maternal mortality. ${ }^{25}$ Legalisation of abortion in 2002 in Nepal, therefore, has a larger role in reduction of maternal mortality. ${ }^{26} \mathrm{~A}$ major decline in maternal mortality in Matlab region of Bangladesh was due to fall in abortion related deaths. ${ }^{27}$ Similarly, maternal mortality ratio fell by $50 \%$ in Romania after legalisation of abortion since $86 \%$ of maternal mortality ratio before were caused by complications from unsafe abortion. ${ }^{28}$

Safe motherhood, service provision and intermediate factors

Following Nairobi Conference of Safe Motherhood in 1987, Nepal formulated the national safe motherhood plan of action and safe motherhood programme was launched by family health division of ministry of health. ${ }^{2}$ It now has a national policy for skilled birth attendants (2006), national safe abortion policy, and safe motherhood and newborn health long term plan (20062017). The safe motherhood programme has received substantial international support and initiated a variety of promotional activities. ${ }^{29}$ Improvement in maternal health has been linked to efforts of safe motherhood activities. ${ }^{30}$

Firstly, there is increased availability and accessibility of maternal health services through an extensive network of district health system: district hospital, primary health care centre, health post and sub-health post, with female community health volunteers at the grass root level. Overall, there is substantial growth in health facilities reaching the peripheral area. ${ }^{31}$ The number of primary health care centres that provides birthing facilities increased more than double from 2004 to 2007. Similarly, number of sites of Basic emergency obstetric care and Comprehensive emergency obstetric care has increased. ${ }^{32}$

Secondly, more human resources for skilled birth attendants have been produced in recent years. Female community health volunteers, who link community with health system by providing advice on family planning, maternal and child health, have been extensively deployed. Maternal and child health worker provides antenatal and postnatal care at sub health post, and they are trained for skilled birth attendant after a short training. ${ }^{33}$ Auxiliary nurse midwife provide antenatal and post natal care at health posts, some of which have birthing centres. Medical officer or health assistant or auxiliary nurse midwife provide antenatal, delivery and postnatal care in primary health care centres, some of which provide Basic emergency obstetric care. However, in the mountainous and hilly regions, availability of human resource especially staff nurse and doctors in health centre is still poor and women do not get the care even after visiting the centres. ${ }^{34}$

Thirdly, free delivery care and safe maternity delivery incentive has increased financial accessibility of women to health service. Safe maternity delivery scheme was introduced in 2005 and provides cash incentive to women who deliver at public and few private facilities. The incentive was mainly targeted to compensate the transport expense and alter women and family's behaviour, to motivate them to come to health facility. However, there are challenges in efficient management of funds, fair distribution and its sufficiency. ${ }^{35}$ Besides, just providing a small fund of money is not long-term service oriented solution.

\section{Non-Utilisation and immediate consequences}

On the other hand, despite availability and free delivery care, tendency of home delivery continues and institutional delivery has not increased much. For example, only $18 \%$ of delivery occurred in health care facility in 2006 whereas the target by 2015 is $60 \%$. The rise in postnatal care is extremely low when compared with antenatal care. There might be either no perceived need, or the facility is far away and care is costly, or peripheral facilities may be perceived of lower quality and not consulted. Since antenatal visits have risen sharply, women just do not go health facilities for delivery because of perceived no benefit by having delivered in accessible lower level facility. Bypassing of peripheral facilities and lack of efficient referral system in health care system of Nepal is quite common. ${ }^{36}$

Disaggregated data by caste, ethnicity, economic status and place of residence has wide disparity in terms of utilisation of maternity services. ${ }^{37}$ Utilisation of skilled care varies from a figure of $33 \%$ in central hill to a low of $8 \%$ in western mountain area. Women in the poorest quintile had approximately 12 times less access to skilled care compared to their richest quintile. ${ }^{38}$ Therefore, even when national data may indicate achievement of MDG, the disaggregate data will be far behind the target. It is mainly due to unequal development among the regions, inequity in resource provisions among the different regions and pocket areas of poverty and marginalised population.

It is well documented that the most maternal deaths occur due to complications around delivery and that institutional help is indispensable to avoid most of the maternal deaths. Many countries, especially the developed ones, reduced maternal mortality significantly by means of providing midwifery care. Sweden developed an expanded network of midwifery service that reached even to household and reduced its maternal mortality significantly early in $19^{\text {th }}$ century. ${ }^{39}$ MMR declined sharply in England, the Netherlands and other 
Karkee. How did Nepal Reduce the Maternal Mortality?

European countries only after availability of antibiotics for infection, blood transfusions for haemorrhage, and improved surgical techniques for caesarean section. ${ }^{12}$ However, Qiu et al. argued that maternal mortality reduction in Zhejiang Province of China corresponded with increase in economic status and improvement in social factors like maternal safety. ${ }^{40}$

There are other strategies that have been shown effective in MMR reduction. Sri Lanka, in particular, established a system of health facilities with midwifery care and family planning services around the country. ${ }^{12}$ MMR declined substantially in a district of Bangladesh as a result of community-based family planning and maternity care.$^{41}$ In Ethiopia, Community based obstetric care that included informed community participation with special attention to prenatal screening through an outreach programme with experienced nurse-midwives, a functionning referral system, and a maternity waiting home for women reduced the number of women going to a tertiary care hospital as well as the maternal mortality. ${ }^{42}$ It seems that the improvement comes when midwifery service is coupled with family planning and safe abortion, and that such service be available at community or even household level. It is paradox to note that without much increase in health facility utilisation, Nepal has reportedly reduced the maternal mortality substantially. This clearly indicates some factors out of the direct health service related factors might have played the significant role. For example, as shown earlier, legalisation of abortion, increased women autonomy, and family planning methods improved in Nepal during past decade and this, in turn, might have contributed positively to improved maternal health. Decline in fertility and high risk pregnancies has been found strongly associated with maternal mortality reduction in Nepal. ${ }^{43}$

\section{CONCLUSION}

According to data from successive NDHS of 1996, 2001 and 2006, Nepal has reduced maternal mortality rate significantly but utilisation of facility delivery services has not increased proportionately. The maternal health improvement is a result of various factors. Especially, there is good indication that the maternal health improvement has resulted more from improvement in intermediate or distal factors rather than improvement in immediate casual factors. With continuation of emphasis in intermediate factors such as age of marriage and family planning, Nepal should focus on strategies on increasing utilisation of quality skilled care and referral chain from household to tertiary facility to continue the decreasing trend, and further reduction of maternal mortality to achieve the MDG.

\section{ACKNOWLEDGEMENTS}

This article is associated with Author's PhD project, which is supported by AusAID through Australian Development Scholarship. The content is solely the responsibility of the author and does not necessarily represent the official views of the scholarship provider. The author is grateful to the anonymous reviewers for helpful comments and improvement of this article. 


\section{REFERENCES}

1. Nepal MK. The Global Campaign for the Health Millennium Development Goals 2010: Putting the global Strategy for women's and children's Health into action. Millennium Development Goals Award recognizes years of declining mortality. 2010 Secretary-General of the United Nations.

2. Pradhan A, Suvedi BK, Barnett S, Sharma SK, Puri M, Paudel P, et al. Nepal Maternal Mortality and Morbidity Study 2008/2009. Ministry of Health and Population, Government of Nepal, Kathmandu, 2010.

3. Graham W, Ahmed S, Stanton C, Abou-Zahr C, Campbell O. Measuring maternal mortality: An overview of opportunities and options for developing countries. BMC Medicine . 2008; 6,1:12.

4. Tsai TC. Public health and peace building in Nepal. Lancet . 2009 374,9689:515-516.

5. Ensor T, Clapham S, Prasai DP. What drives health policy formulation: Insights from the Nepal maternity incentive scheme? Health Policy. 2009; 90,2-3:247-253.

6. Singh S. Impact of long-term political conflict on population health in Nepal. CMAJ, 2004; 171,12:1499-1501.

7. Puri M, Frost M, Tamang J, Lamichhane P, Shah I. The prevalence and determinants of sexual violence against young married women by husbands in rural Nepal. BMC Research Notes. 2012; 5,1:291.

8. McCarthy J, Maine D. A Framework for Analyzing the Determinants of Maternal Mortality. Stud Family Plann. 1992; 23,1:23-33.

9. Macro International Inc. Trends in Demographic and Reproductive Health Indicators in Nepal. Calverton, Maryland, : Macro Internations Inc. USA; 2007

10. Ronsmans C, Graham WJ. Maternal mortality: who, when, where, and why. Lancet 2006 368,9542:1189-1200.

11. Campbell OMR, Graham WJ. Strategies for reducing maternal mortality: getting on with what works. Lancet . 2006; 368,9543:1284-1299.

12. WHO. Reduction of Maternal Mortality. A joint WHO/UNFPA/UNICEF/World Bank Statement Geneva: World Health Organisation; 1999.

13. Bhandari GP, Premarajan KC, Jha N, Yadav BK, Paudel IS, Nagesh S. Prevalence and determinants of unmet need for family planning in a district of eastern region of Nepal. Kathmandu Univ Med J. 2006; 4,2:203-10.

14. Aryal TR. Age at first marriage in Nepal: differentials and determinants. J Biosoc Sci. 2007; 39,5:693-706.

15. Central Bureau of Statistics. Statistical Pocket Book Nepal. 2010, Government of Nepal, National Planning commission Secretariat, Kathmandu.
16. Furuta M, Salway S. Women's position within the household as a determinant of maternal health care use in Nepal. Int Fam Plan Perspect 2006; 32,1:17-27.

17. Brunson J. Confronting maternal mortality, controlling birth in Nepal: The gendered politics of receiving biomedical care at birth. Soc Sci Med , 2010; 71,10:1719-1727.

18. Kim choe M, Thapa S, Mishra V. Early marriage and early motherhood in Nepal. J Biosoc Sci. 2005 ; 37,02:143-162

19. Christian P, Katz J, Wu L, Kimbrough-Pradhan E, Khatry SK, LeClerq SC, et al. Risk factors for pregnancy-related mortality: A prospective study in rural Nepal. Public Health. 2008; 122,2:161-172.

20. Sharma SK, Sawaingdee Y, Sirirassamee B. Access to Health: Women's Status and Utilization of Maternal Health Services in Nepal. J Biosoc Sci. 2007 39,05:671-692

21. Allendorf K. Do Women's Land Rights Promote Empowerment and Child Health in Nepal? World Dev. 2007; 35,11:1975-1988.

22. Thapa S. Safe abortion services in Nepal: initial years of availability and utilization. World Health Pop. 2010; 11,3:55-68.

23. Thapa PJ, Thapa S, Shrestha N. A Hospital-Based Study of Abortion in Nepal. Stud Family Plann. 1992; 23,5:311-318.

24. Lamichhane P, Harken T, Puri M, Darney PD, Blum M, Harper CC, et al. Sex-selective abortion in Nepal: a qualitative study of health workers' perspectives. Women Health Issu. 2011; 21(3 Suppl):S37-41.

25. 25. Pant PD, Suvedi BK, Pradhan A, Hulton L, matthews Z, Maskey M. Investigating Recent Improvements in Maternal Health in Nepal: Further Analysis of the 2006 Nepal Demographic and Health Survey. Calverton, Maryland, USA: Macro International Inc.; 2008.

26. Shakya G, Kishore S, Bird C, Barak J. Abortion Law Reform in Nepal: Women's Right to Life and Health. Repro Health Matt 2004; 12(24, Supplement 1):75-84.

27. Chowdhury ME, Botlero R, Koblinsky M, Saha SK, Dieltiens G, Ronsmans C. Determinants of reduction in maternal mortality in Matlab, Bangladesh: a 30-year cohort study. The Lancet 2007; 370,9595:1320-1328.

28. Hord C, David HP, Donnay F, Wolf M. Reproductive Health in Romania: Reversing the Ceausescu Legacy. Stud Family Plann. 1991; 22,4:231-240.

29. Levitt M, Russel n. Mobilizing for safe motherhood in Nepal. World Health Statistics. 1998; 51,1:16.

30. Barker CE, Bird CE, Pradhan A, Shakya G. Support to the Safe Motherhood Programme in Nepal: An 
Integrated Approach. Reprod Health Matter . 2007; 15,30:81-90.

31. Karkee R, Jha N. Primary Health Care Development: where is Nepal after 30 years of Alma Ata Declaration. JNMA. 2010; 49,178:178-84.

32. Ministry of Health and Population (MoHP) [Nepal]. Annual Report of Department of Health Services. Kathmandu, Government of Nepal; 2009.

33. Carlough M, McCall M. Skilled birth attendance: What does it mean and how can it be measured? A clinical skills assessment of maternal and child health workers in Nepal. Int J Gynecol Obstet. 2005; 89,2:200-208.

34. RTI International. Human Resource Strategy Options for Safe Delivery . 2009 Research Triangle Park, NC, USA.

35. Powell-Jackson T, Morrison J, Tiwari S, Neupane B, Costello A. The experiences of districts in implementing a national incentive programme to promote safe delivery in Nepal. BMC Health Serv Res. 2009; 9,1:97.

36. Furber AS. Referral to hospital in Nepal: 4 years' experience in one rural district. Trop Doct. 2002; 32,2:75-78.
37. 37. Dhakal S. Maternal mortality falls in Nepal but inequalities exist. Lancet, 2007; 370,9595:1301-1301.

38. Ministry of Health and Population (MoHP) [Nepal], New Era, Inc MI. Nepal Demographic and Health Survey 2006. 2007. Kathmandu Nepal: Ministry of Health and population (Government of Nepal), New ERA, and Macro International Inc.

39. Hogeberg U, Wall S. Secular Trends in Maternal Mortality in Sweden from 1750 to 1980 . B World Health Organ. 1986; 64,3:79-84.

40. Qiu L, Lin J, Ma Y, Wu W, Qiu L, Zhou A, et al. Improving the maternal mortality ratio in Zhejiang Province, China, 1988-2008. Midwifery. 2010; 26,5:544-548.

41. Fauveau V, Stewart K, Khan S. Effect on mortality of community-based maternity care programme in rural Bangladesh. Lancet . 1991; 338:1183-6.

42. Koblinsky M, Tinker A, Daly P. Programming for Safe Motherhood: a guide to action. Health Pol Plann. 1994; 9,3:252-266.

43. Hussein J, Bell J, Dar Iang M, Mesko N, Amery J, Graham W. An Appraisal of the Maternal Mortality Decline in Nepal. PLoS ONE. 2011; 6,5. 